\title{
An efficient method for a delayed and accurate characterization of snow grains from natural snowpacks
}

\author{
E. BRUn AND E. PAHAUT \\ Meteo-France CNRM, Centre d'Études de la Neige, 38406 Saint-Martin-d'Hères Cedex, France
}

\begin{abstract}
The authors describe a new method that allows an accurate, cheap and quick characterization of snow grains from natural snowpacks. The method is based on stopping all metamorphism of snow grains by immersing them in cold isooctane. Snow grains are then carried from the field, stored in a cold room and easily observed through a microscope. It then makes possible recording of snow-grain pictures in a state similar to their natural state, even after storage of several months.
\end{abstract}

\section{INTRODUCTION}

Snow-grain morphology is one of the most important parameters for investigating snowpack properties. It strongly influences or governs mechanical properties, settlement rate and snow-radiation properties.

During the last 10 years, electronic thermometers and dielectric sensors have made it possible to measure accurately and quickly temperature and liquid watercontent profiles of the snow cover. Snow characterization is not as easy in the field. Magnifying glasses do not magnify sufficiently to recognize accurately the intermediate types of snow and to obtain an unbiased measurement of their size. The field microscope can only be used under special meteorological conditions to avoid melting or sublimation during snow handling: no wind and cold weather. It cannot be used easily on steep slopes.

Thin or plane sections are widely used by important laboratories for analysing the snow micro-structure. This method is very efficient for measuring the stereological parameters such as point density and intercept length (Dozier and others, 1987; Good, 1987). However, each analysis requires tedious work using expensive devices. Furthermore, this method does not allow classification of snow samples according to the different types of the international snow classification (Colbeck and others, 1990). More recently, Good and others (1991) have developed an original heating cutter to obtain $5 \mathrm{~cm}$ thick slices of the snow cover that can be observed using transparency to the Sun's rays. This method is very efficient for exhibiting snow-cover stratigraphy, especially the thin layers that cannot be easily seen in a traditional pit. However, this method does not allow description of snow grains according to the international snow classification.

The purpose of this paper is to describe a simple and low-cost method that enables retrieval of snow grains from the field and carrying them to a cold room where they can be stored and then analysed under the microscope, remaining in their natural state for several months.

\section{DESCRIPTION OF THE METHOD}

The method used to collect, store and analyse snow grains taken from a natural snowpack includes different stages:

$5 \mathrm{cl}$ flasks are filled with liquid iso-octane (trimethyl 22-4-pentane) at a sub-freezing temperature.

The flasks are put in an insulated box that is refrigerated by small $\mathrm{CO}_{2}$-snow masses. A weight of $300 \mathrm{~g}$ of $\mathrm{CO}_{2}$-snow is sufficient to retain the temperature inside the box below $0^{\circ} \mathrm{C}$ up to $24 \mathrm{~h}$. The total weight of the box is less than $3 \mathrm{~kg}$, ensuring easy carrying within a rucksack.

After having made a snow pit or at a snow-cover

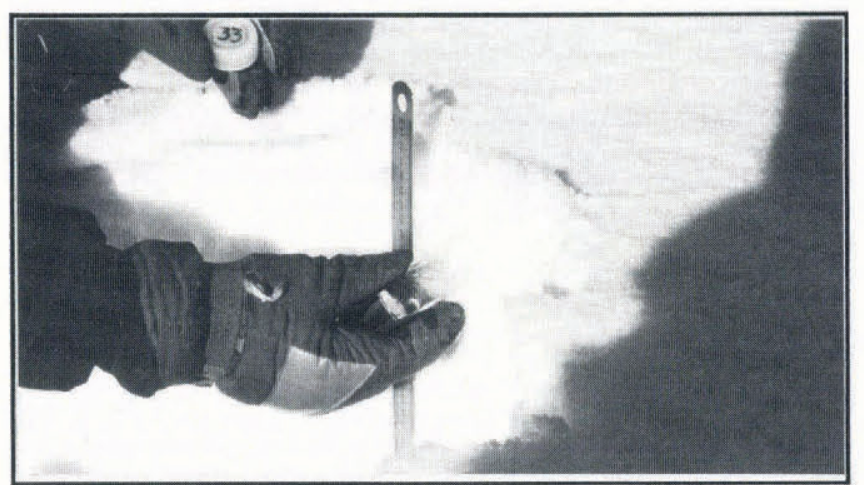

Fig. 1. Operator collecting snow samples in the field in an iso-octane flask. 
surface, snow grains are taken from a layer and collected in an iso-octane flask (Fig. 1). The flask is immediately placed in the cold box. From this time, the wetting of the snow-grain surface by cold isooctane inhibits all metamorphism and the shape of the grains does not change significantly as long as the grains remain immersed and the temperature remains below $0^{\circ} \mathrm{C}$. This derives from the fact that the wetting is efficient enough to avoid any vapour transfer at the ice surface. Only volume or surface diffusion of the ice can occur and they are known as very slow processes. Furthermore, no significant chemical reaction occurs between the ice and iso-octane. The duration of the transport does not matter as long as the flasks remain at a sub-freezing temperature. They are stored in a cold room for several months.

To analyse a snow sample, the contents of the flask are poured over a filter that retains snow grains. The isooctane remaining at the ice surface evaporates very quickly. The grains are placed within a closed glass box and analysed under a microscope. From this time, they continue by submitting to metamorphism. However, ice sublimation is limited by closing the glass box. The observer has sufficient time to determine easily the type and the size of the snow grains, and also to record pictures of the grains on a video tape. These records can be analysed by pictureprocessing on a computer, in order to measure automatically the sizes of the grains or different parameters such as area, mean radius of curvature, perimeter or inertial moments.

Figure 2 shows pictures of snow grains treated by the present method and analysed several weeks after they had been collected in the field.
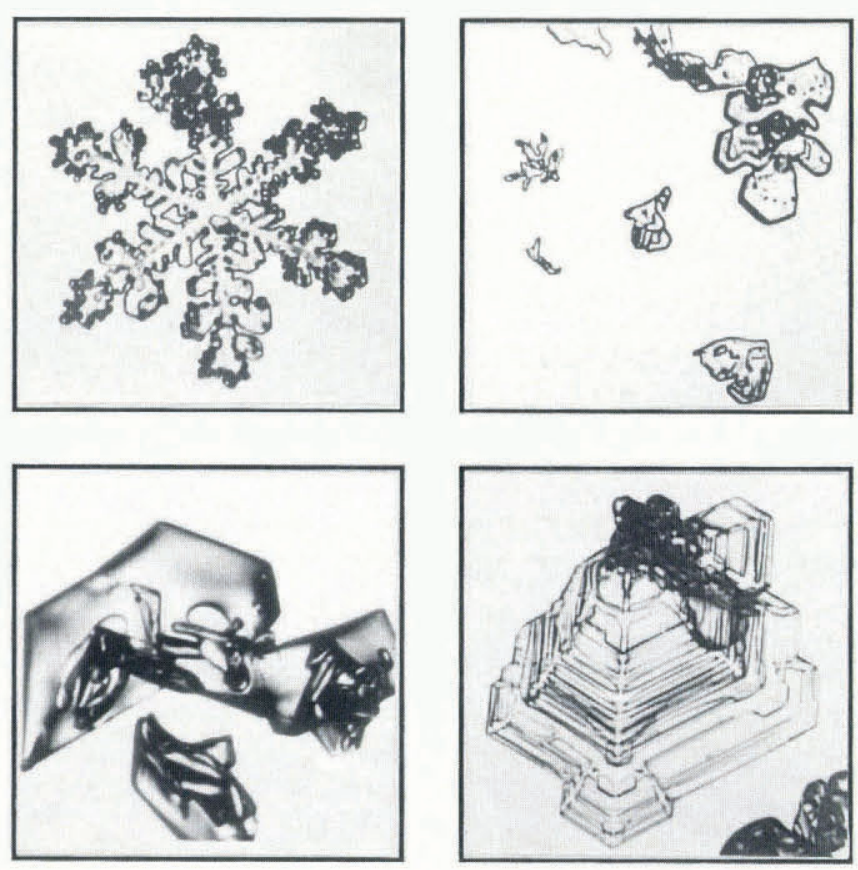

Fig. 2. Examples of grains collected from natural snowpacks and observed after several weeks' storage in cold iso-octane.

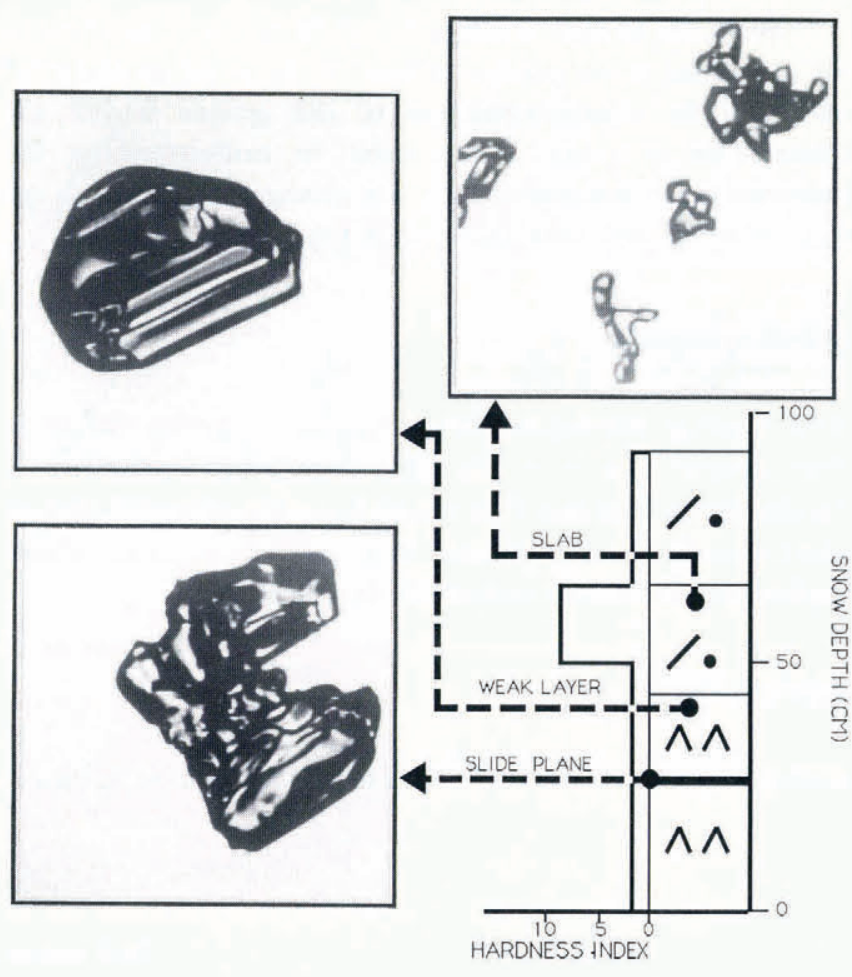

Fig. 3. Use of the storage method to analyse a stratigraphical profile during an avalanche investigation. The method allows an accurate and easy way to determine the causes of instability.

\section{FIELDS OF USE}

The present method can be used efficiently for different purposes; each time it is necessary to obtain a detailed description of the snow grains.

We have also used it to follow the evolution of snow layers at a given location during a whole winter season. Once each week, after having made a snow pit, samples have been collected from each layer of the snowpack and carried to the cold laboratory, following the method described in this paper. Their characterization under the microscope has allowed us to evaluate our ability to simulate snow metamorphism using a numerical model.

This method is also used to conduct "avalanche investigations" after an accident. Figure 3 shows the quality of the stratigraphical description of the snowpack that enables an accurate determination of the source of instability.
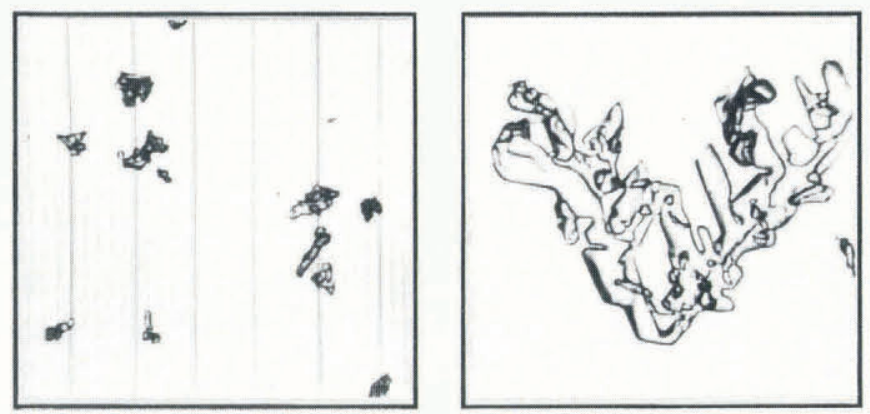

Fig. 4. Grains collected directly in iso-octane from a snowdrift. 
Since the winter of 1989-90, we have used this method for collecting snow grains carried by the wind during drift events. The characterization of the grains under the microscope in a cold room assists in understanding the mechanism of snowdrift and the changes in grain shape during drift. Figure 4 shows such grains.

\section{CONCLUSION}

The method developed for storing snow grains collected over several months in the field opens a wide field of use. Its simplicity and low cost makes it a very powerful tool to characterize snow grains from remote areas where sophisticated devices cannot be handled easily.

\section{REFERENCES}

Colbeck, C. and 7 others. 1990. The international classification for seasonal snow on the ground. Wallingford, Oxfordshire, International Association of Hydrological Sciences. International Commission on Snow and Ice.

Dozier, J., R.E. Davis and R. Perla. 1987. On the objective analysis of snow microstructure. International Association of Hydrological Sciences Publication 162 (Symposium at Davos 1986 - Avalanche Formation, Movement and Effects), 49-59.

Good, W. 1987. Thin sections, serial cuts and 3-D analysis of snow. International Association of Hydrological Sciences Publication 162 (Symposium at Davos 1986 - Avalanche Formation, Movement and Effects), 35-48.

Good, W., G. Krusi and J.V. Niederhausern. In press. Préparation et analyse de profils stratigraphiques à contrastes élevés. Proceedings of Symposium ANENA CISAIKAR, Chamonix, June 1991.

The accuracy of references in the text and in this list is the responsibility of the authors, to whom queries should be addressed.

MS received 8 July 1991 